\title{
Concurrent chromatographic determination of pseudoephedrine and loratadine from combination syrups and tablets
}

\author{
Imad Osman Abu Reid(1)
}

\begin{abstract}
Background: Chromatographic separation of polar and nonpolar compounds when presented in combined dosage forms has always been considered as great analytical challenge. Separation and retention of both polar and nonpolar compounds by the same stationary phase can be a useful approach for analyses of complex samples with such a difference in chemical properties. Loratadine (nonpolar) and pseudoephedrine (polar) are typical examples of this situation.

Results: The Box-Behnken design was used to optimize the separation process, an efficient separation of loratadine and pseudoephedrine was achieved within 6 min; employing a mixture of $16.0 \mathrm{mM}$ ammonium acetate buffer (pH 4.5) and acetonitrile $(23: 77, \mathrm{v} / \mathrm{v})$ as isocratic mobile phase, pumped at $1.0 \mathrm{~mL} / \mathrm{min}$ through a Zorbax cyanopropyl column $(250 \mathrm{~mm} \times 4.6 \mathrm{~mm}, 5 \mu \mathrm{m})$, the analytes were detected at $250 \mathrm{~nm}$. Under the same conditions, separation of sodium benzoate preservative co-formulated with the two analytes in syrup formulation was also achieved. The calibration curve demonstrated excellent linearity in the range of $24.6-123.2 \mu \mathrm{g} / \mathrm{mL}$ and $594.8-2974.0 \mu \mathrm{g} / \mathrm{mL}$ for loratadine and pseudoephedrine, respectively with determination coefficient $\left(r^{2}\right)>0.999$.
\end{abstract}

Conclusion: The method's accuracy bias $<2.0 \%$, repeatability and intermediate precision (\%RSD $<2.0 \%$ ) were verified. In addition, system suitability parameters were found within the acceptable limits. Satisfactory results were obtained upon the application of the validated method to the analysis of commercial tablet and syrup formulations.

Keywords: Pseudoephedrine, Loratadine, Experimental design, Liquid chromatography

\section{Background}

Loratadine (LOR) chemically is ethyl 4-(8-chloro-5,6dihydro-11-H-benzo -[5,6] cyclohepta[1,2-b] pyridin-11ylidene)-1-piperidine-carboxylate (Fig. 1a). It is a longacting, non-sedative second-generation $\mathrm{H}_{1}$ receptor blocker with no significant antimuscarinic activity. It is used for the symptomatic relief of allergic conditions including rhinitis and chronic urticaria [1].

Pseudoephedrine (PSE) chemically is (1S, 2S)-2-(Methyl-amino)-1-phenylpropan-1-ol (Fig. 1b). Pseudoephedrine is a sympathomimetic agent with both direct

Correspondence: iabureid@hotmail.com

Department of Pharmaceutical Chemistry, Faculty of Pharmacy, University of Khartoum, P.O. Box 1996, Khartoum, Sudan and indirect actions [1]. Salts of pseudoephedrine are given orally for the symptomatic relief of nasal congestion; it is combined with other ingredients in preparations intended for the relief of cough and cold symptoms.

Combined dosage forms of loratadine and pseudoephedrine sulfate are prescribed to relieve symptoms of allergic rhinitis [1]. Their commercial association exhibits important mass difference between the two analytes (PSE: LOR up to 24:1, w/w). Liquid formulations in addition to the two active contain preservatives such as methylparaben (MP), prorylparaben (PP), or sodium benzoate $(\mathrm{SB})$. All these aspects increase the analytical challenge.

\section{Springer Open}

(c) The Author(s). 2021 Open Access This article is licensed under a Creative Commons Attribution 4.0 International License, which permits use, sharing, adaptation, distribution and reproduction in any medium or format, as long as you give appropriate credit to the original author(s) and the source, provide a link to the Creative Commons licence, and indicate if changes were made. The images or other third party material in this article are included in the article's Creative Commons licence, unless indicated otherwise in a credit line to the material. If material is not included in the article's Creative Commons licence and your intended use is not permitted by statutory regulation or exceeds the permitted use, you will need to obtain permission directly from the copyright holder. To view a copy of this licence, visit http://creativecommons.org/licenses/by/4.0/. 


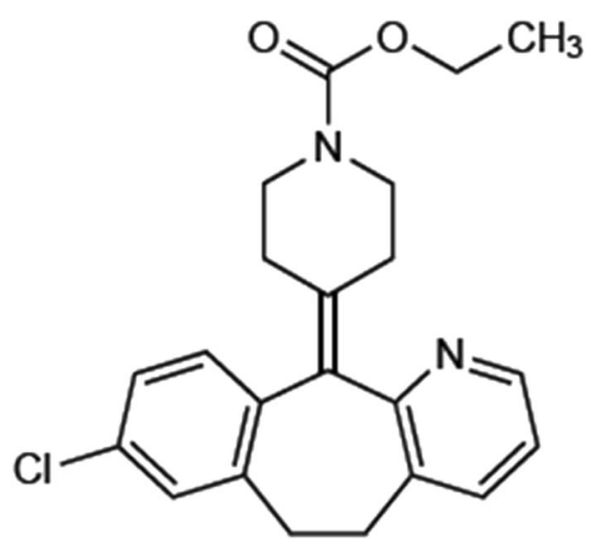

a)

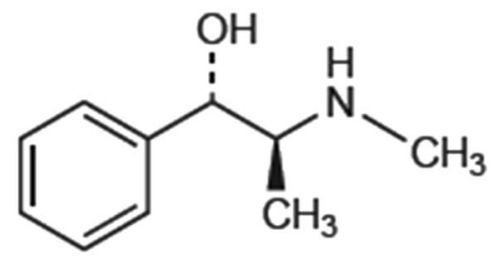

b)

Fig. 1 Chemical structure of a loratadine and $\mathbf{b}$ pseudoepehedrine

Pseudoephedrine is characterized by being highly polar ( $\log \mathrm{P}=0.9$ ), while loratadine is highly apolar $(\log \mathrm{P}=5.20)$ [2]. This great difference in polarity between the two compounds offers another interesting analytical challenge when subjected to chromatographic analysis.

The combination of LOR and PSE in syrup formulation is not official in any pharmacopeia, and it is not commonly used worldwide; accordingly, no analytical method so far has been developed for their determination in liquid formulations; only few reversed-phase chromatographic methods have been developed for the determination of the two analytes in tablets [3-5]. The other analytical techniques reported were multiwavelength spectroscopy [3], first derivative spectroscopy [5], chemometric treatment of spectrophotometric data [6], analysis of nonlinear second-order spectrophotometric data generated by a $\mathrm{pH}$-gradient flow injection technique and artificial neutral networks [7], highperformance thin layer chromatography [8], and cationexchange chromatography [9].

The reported reversed-phase chromatographic methods [3,5] were not efficient enough to obtain optimum separation between the two analytes; in both methods under reversed-phase conditions, the hydrophilic component PSE has eluted with the solvent front, indicating insignificant retention and possible interference with the formulation; while the retention of LOR was sacrificed leaving it to elute late. To overcome this problem and to achieve optimum separation between the two analytes in tablet formulation, an expensive approach which is also not suitable for routine application was developed where a $\mathrm{C}_{18}$ and cyanopropyl column were used in series [4].
The objective of the present work was to develop and validate a high-performance liquid chromatographic methodology for the simultaneous determination of LOR and PSE in tablets and syrups with significant retention of the compounds in a single isocratic run without the use of ion-pairing agents or micellar liquid chromatography and without interference from sodium benzoate preservative in case of syrup formulation.

\section{Methods}

\section{Apparatus and software}

The separations were performed on a Shimadzu Prominence high-performance liquid chromatography (HPLC) system consisted of degasser (Model DGU-20A5), pump (Model LC-20AD), Rheodyne manual injector fitted with $20-\mu \mathrm{L}$ loop, variable wavelength UV-Vis detector (Model SPD-20A). The separation was carried out on a Zorbax CN column $(250 \mathrm{~mm} \times 4.6 \mathrm{~mm}, 5 \mu \mathrm{m})$. The mobile phase was pumped at a flow rate of $1.0 \mathrm{~mL} / \mathrm{min}$, and the analytes were monitored at $250 \mathrm{~nm}$.

The experimental design data analysis and response surface was performed with Design Expert v. 8.1 (StatEase Inc., Minneapolis, MN, USA). Other statistical analyses were carried out using Microsoft Excel 2013 software (Microsoft, USA).

\section{Chemicals and reagents}

Analytical-grade reagents ammonium acetate $(\mathrm{BDH}$, Poole, England), glacial acetic acid acid (Sd fine Chem. Ltd., India), acetonitrile HPLC grade (Scharlau Chemie, Spain), and double-distilled water were used throughout the chromatographic analysis. Aqueous acetonitrile solution $(75 \% \mathrm{v} / \mathrm{v})$ was used as a diluent. 


\section{Pure drugs}

The reference standards of loratadine (99.5\%), sodium benzoate (99.7\%), and pseudoephedrine sulphate (98.8\%) were used in this work.

\section{Formulations}

Marketed formulations Lorinase syrup with label claim pseudoephedrine sulphate $60 \mathrm{mg}$ and loratadine $5 \mathrm{mg}$ per $5 \mathrm{~mL}$, and Clarinase tablets labeled to contain $5 \mathrm{mg}$ loratadine and $120 \mathrm{mg}$ pseudoephedrine sulphate per tablet were purchased from the local market.

\section{Preparation of standards and sample solutions Optimization standard solution}

Ten milliliters of a $100 \mu \mathrm{g} / \mathrm{mL}$ loratadine standard solution in acetonitrile were transferred into a $100-\mathrm{mL}$ volumetric flask containing $5 \mathrm{mg}$ sodium benzoate and 90 mg pseudoephedrine sulphate; the content was mixed and made to volume with the diluent.

\section{Standards stock solution}

Accurately weighed about $340 \mathrm{mg}$ pseudoephedrine sulphate, $5 \mathrm{mg}$ sodium benzoate, and $15 \mathrm{mg}$ loratadine standards were transferred into a $25-\mathrm{mL}$ volumetric flask; $10 \mathrm{~mL}$ of the diluent were added. The content of the flask was sonicated for $5 \mathrm{~min}$ and allowed to cool, and the volume was adjusted to the mark with the same diluent.

\section{Sample preparation \\ Syrup}

The sample density was first determined, and sample weight equivalent to $5 \mathrm{~mL}$ was accurately weighed into a $50-\mathrm{mL}$ volumetric flask; $10 \mathrm{~mL}$ of the diluent were added, and the content was mixed and completed to mark with the same diluent. The sample was then filtered through $0.45-\mu \mathrm{m}$ nylon filter and injected into the HPLC system. The concentrations of LOR and PSE were calculated from the linear regression equations of their calibration curves.

\section{Tablets}

Ten tablets were finely powdered, and a portion equivalent to one tablet was suspended in $10 \mathrm{~mL}$ water in a 50-mL volumetric flask. The suspension was sonicated for $15 \mathrm{~min}$, and the volume was completed to mark with acetoniltrile. The resulting solution was filtered through a $0.45-\mu \mathrm{m}$ nylon filter and injected into the HPLC system. The concentrations of LOR and PSE were calculated from the linear regression equations of their calibration curves.

\section{Calibration curve}

Aliquot volumes (1-5 mL) of the standard stock solution were transferred into a series of $25-\mathrm{mL}$ volumetric flasks, and volumes were adjusted to the mark with the diluent.

\section{Ammonium acetate buffers}

The different concentrations of the buffer used were prepared by dissolving the required amount of the ammonium acetate in $500 \mathrm{~mL}$ distilled water. The $\mathrm{pH}$ of these buffers was adjusted using dilute glacial acetic acid.

\section{Procedure}

\section{Method development}

The influence of the mobile phase components on chromatographic resolution between the analytes was studied using the following conditions: ionic strength (10, 15, and $20 \mathrm{mM}), \mathrm{pH}(3.5,4.0,4.5$, and 5.0), and percent acetonitrile $(65,70,75$, and $80 \%)$. The experiments were carried by varying one parameter while keeping the other two constant. The resolutions between the adjacent peak pairs were calculated and plotted as a function of the experimental conditions.

\section{Optimization of the mobile phase composition}

The Box-Behnken experimental design [10] was used to optimize the mobile phase composition. The experiments were carried out using a series of mobile phases containing ammonium acetate buffer (10-20 mM) adjusted to $\mathrm{pH}=3.0-5.0$ and acetonitrile (74-80\%),

\section{Method validation}

The optimized method was validated in agreement with the ICH guidelines [11]. The method linearity in the relevant working ranges, precision, accuracy, and specificity were evaluated. System suitability parameters were also determined.

\section{Linearity}

The method's linearity was evaluated using five standard mixtures prepared from their corresponding stock solution to obtain final concentrations of PSE in the range of 594.8-2974.0 $\mu \mathrm{g} / \mathrm{mL}$ and LOR 24.6-123.2 $\mu \mathrm{g} / \mathrm{mL}$. The method of least squares was used to obtain the linearity parameters from calibration data of the analyte concentration versus their corresponding peak areas.

\section{Precision}

Six replicate determinations of the samples containing $100 \%$ of their corresponding expected concentrations in the pharmaceutical product were injected, and the method's precision was verified in its repeatability and intermediate precision aspects according to the $\mathrm{ICH}$ guidelines. For verification of the intermediate precision, 
the process was repeated on a different day using fresh reagents and samples.

\section{Accuracy}

The method accuracy was demonstrated using the standard addition method by evaluating analyte recoveries from a pre-assayed pharmaceutical formulation sample, containing $60 \%$ of the declared amount of the drugs, which was fortified with known amounts of the two analytes, to obtain concentration levels of $60-120 \%$ of the expected drug concentrations in the pharmaceutical dosage form.

\section{Limits of detection LOD and quantification LOQ}

In order to assess that the validated concentration ranges of the analytes were above their LOQ values, the LOD and LOQ were determined employing the ICH method based on the calibration curve [11].

\section{System suitability parameters}

The system suitability parameters: the column efficiencies $(\mathrm{N})$, resolution between adjacent peeks $\left(\mathrm{R}_{\mathrm{s}}\right)$, and asymmetry factor $\left(A_{s}\right)$ were calculated from five replicate injections of the standard solution made under optimized conditions.

\section{Results}

\section{Method development and optimization}

Preliminary investigations using the one-factor-at-a-time (OFAT) approach caused variable effects on the retention of the analytes with organic modifier content (acetonitrile) when the $\mathrm{pH}$ was kept at 4 and the ionic strength at $10 \mathrm{mM}$. The retention of PSE increased, while that of LOR and sodium benzoate decreased with increasing acetonitrile proportion. Pseudoephedrine retention behavior is opposed to reversed-phase retention mechanism, where solutes are retained less as the polarity of the mobile phase decreases (when increasing organic modifier content). This observation could lead to the assumption that pseudoephedrine is in fact retained by the cyanopropyl stationary phase in accordance to a normal-phase mechanism as normal-phase mechanism supposes a polar stationary phase, a nonpolar mobile phase, and a polar solute. Cyanopropyl radicals are in fact quite polar in character, however behaving in both reversed-phase and normal-phase mechanisms [12]. Since pseudoephedrine is a hydrophilic molecule which will fully ionize at $\mathrm{pH}$ of 4 , all these considerations support the idea of a pseudo-normal phase separation mechanism for pseudoephedrine, mainly for a higher organic modifier content in the mobile phase. With acetonitrile proportions greater than $70 \% \mathrm{v} / \mathrm{v}$ LOR and PSE are eluted in the opposite order with PSE being retained more than LOR; that is, the dominant mechanism is typically reversed-phase interaction.

Variation of the acetate buffer $\mathrm{pH}$ in the range of 3.5 to 5.0 while keeping the acetonitrile proportion at $70 \%$ $\mathrm{v} / \mathrm{v}$ and the ionic strength at $10 \mathrm{mM}$ did not affect the retention of the analytes or the resolution between them; with LOR being a weaker base as compared with PSE, it elutes first since it is protonated at the $\mathrm{pH}$ range studied, indicating reversed-phase interaction as possible mechanism for its retention.

Variation of the ionic strength in the range of 10-20 $\mathrm{mM}$ while keeping the $\mathrm{pH}$ at 4.0 and acetonitrile percentage at $70 \% \mathrm{v} / \mathrm{v}$ did not affect the retention of LOR and SB while the retention of PSE has increased with increasing the ionic strength. The increase of the ionic strength leads to higher retention of the polar compounds by increasing the polarity of the medium and the dissociation of compounds. This means that the acids are more negatively charged and the basic drugs are more positively charged. The basic and acidic drugs become stronger bases and acids, respectively. The net results are stronger retention for the basic drugs by electrostatic attraction and decreased retention for the acidic drugs by repulsion [13].

To obtain second-order predictive models, the BoxBehnken design [10] was employed. The optimum composition of the mobile phase was determined with series of mobile phases containing acetonitrile in the range of $(74-80 \% \mathrm{v} / \mathrm{v})$, ammonium acetate buffer $(10-20 \mathrm{mM})$ with its $\mathrm{pH}$ being varied between 3 and 5 . The resolutions between the adjacent peak pairs were considered as the responses for the optimization purpose. The criteria for optimization of each response are given in Table 1.

The resolution between SB and LOR peak pair was kept as 4.0 to ensure sufficient resolution of the preservative peak in the sample from LOR peak; the resolution between LOR and PSE pair was kept as 5.0 to ensure sufficient resolution between the peak pair and reasonable analysis time. Importance of 3.0 was considered in both cases; as from the preliminary studies, there is no critical resolution between the analyte pairs to warrant considering more importance value.

The relation between the investigated factors and selected responses was established using multiple linear regressions and the least-squares method of approximation. The obtained models were then reduced

Table 1 Criteria for the optimization of individual responses

\begin{tabular}{lllll}
\hline Response & Criteria & & \\
\cline { 2 - 5 } & Lower limit & Upper limit & Goal & Importance \\
\hline$Y_{1}$ & 1.11 & 5.08 & 4.00 & 3 \\
$Y_{2}$ & 2.54 & 15.00 & 5.00 & 3 \\
\hline
\end{tabular}


by backward elimination, omitting the insignificant factors (those having $\mathrm{P}$ values $>0.05$ ). The newly obtained equations in terms of coded factor values were as follows:

$$
\begin{aligned}
& \mathrm{Y}_{1}=+4.22-0.36 \mathrm{~A}-0.094 \mathrm{~B}-1.04 \mathrm{C}-0.73 \mathrm{AC} \\
&+0.52 \mathrm{~B}^{2}-0.60 \mathrm{C}^{2} \\
& \log _{10}\left(\mathrm{Y}_{2}\right)=+0.77-0.11 \mathrm{~B}+0.19 \mathrm{C}
\end{aligned}
$$

where $Y_{1}=$ resolution between $\mathrm{SB}$ and LOR and $\log _{10}$ $\left(\mathrm{Y}_{2}\right)=\log$ base 10 of resolution between LOR and PSE. It is important to notice that the best fit model equation for the resolution between LOR and PSE was possible after log base 10 transformations of the responses.

Since two responses (resolution between two peak pairs) at the same time, Derringer's desirability function was used [14]. The design space generated through the desirability function is portrayed in Fig. 2 indicating high method performance owing to maximum desirability value (equal to 1); accordingly, it was possible to conclude that there was a set of coordinates producing high desirability $(\mathrm{D}=1.0)$. These were $\mathrm{pH}$ of 4.5 , acetonitrile content of $77 \%$, and ionic strength of $16.0 \mathrm{mM}$. The predicted response values corresponding to the latter value of $\mathrm{D}$ were $\mathrm{Y}_{1}=4.0$ and $\mathrm{Y}_{2}=5.6$.

\section{Method validation}

\section{Linearity}

The calibration curves correlation coefficients were higher than 0.99 , the confidence intervals of the intercepts contained the zero, and the residuals were spread uniformly and at random around the regression lines, passing the normality distribution test $(P<0.05)$ confirming method linearity. The regression parameters of the method are shown in Table 2.

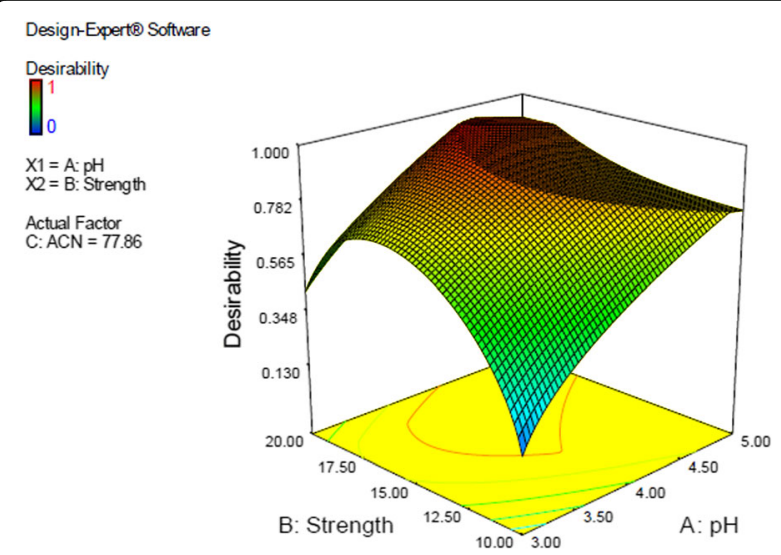

Fig. 2 Graphical representation of overall desirability function ( $D=$ 1), where $\mathbf{A ~ p H}=4.5$, B ionic strength $=16.0 \mathrm{mM}$, and $\mathbf{C}$ perect acetonirile content $=77.0 \%$
Table 2 Linearity data of the developed method

\begin{tabular}{lll}
\hline Parameter & LOR & PSE \\
\hline $\begin{array}{l}\text { Concentration range }(\mu \mathrm{g} / \mathrm{ml}) \\
\text { Linearity-regression equation }\end{array}$ & $24.6-123.2$ & $594.8-2974.0$ \\
$\quad$ Slope $(\mathrm{b})$ & 41254.72 & 652.25 \\
Intercept $(\mathrm{a})$ & 32378.07 & 26284.37 \\
Correlation coefficient $\left(\mathrm{r}^{2}\right)$ & 0.9997 & 0.9998 \\
Standard deviation of the slope $\left(\mathrm{s}_{\mathrm{b}}\right)$ & 468.93 & 7.11 \\
Standard deviation of the intercept $\left(\mathrm{s}_{\mathrm{a}}\right)$ & 37736.65 & 13816.29 \\
Limit of detection $(\mu \mathrm{g} / \mathrm{mL})$ & 2.92 & 67.68 \\
Limit of quantitation $(\mu \mathrm{g} / \mathrm{mL})$ & 8.86 & 205.09 \\
\hline
\end{tabular}

\section{Limits of detection (LOD) and quantification (LOQ)}

The LOD values were $2.92 \mu \mathrm{g} / \mathrm{mL}$ and $67.68 \mu \mathrm{g} / \mathrm{mL}$ with their corresponding LOQ values of $8.86 \mu \mathrm{g} / \mathrm{mL}$ and $205.09 \mu \mathrm{g} / \mathrm{mL}$ for LOR and PSE, respectively as shown in Table 2 . The values were calculated according to the $\mathrm{ICH}$ method using the regression data [11].

\section{Precision}

Low percent relative standard deviation (\%RSD) $(<2 \%)$ values were obtained for the two analytes in repeatability and intermediate precision studies. The overall \%RSD of the assays calculated using the data from the two-day analysis (12 samples) was also $<2 \%$, and the difference between the individual assay results was less than $<2 \%$ (Table 3). This evidenced that the outcome of the determination was statistically similar regardless the day of the assay and reagent preparation in the determination.

\section{Accuracy}

The suitability of method for accurate determination of the analytes was confirmed by the low \%RSD values (< $2 \%)$ with $<2 \%$ variation between the individual samples as shown in Table 3.

\section{System suitability parameters}

The method performance parameters, the column efficiencies $(\mathrm{N})$, resolutions between adjacent peak pairs $\left(R_{s}\right)$, and asymmetry factor $\left(A_{s}\right)$ are listed in Table 4 .

\section{Analysis of commercial formulations}

The results of analysis of commercial formulations were found to be satisfactory as per label claim with standard deviation values below $2 \%$ (Table 3 ). This method also offers the possibility of quantitative determination of sodium benzoate in syrup formulation since it is completely resolved from the loratadine peak eluting next to it. 
Table 3 Determination of accuracy and precision

\begin{tabular}{|c|c|c|}
\hline \multirow[t]{2}{*}{ Parameter } & LOR & PSE \\
\hline & $\% \mathrm{LC} \pm \mathrm{SD}$ & $\% \mathrm{LC} \pm \mathrm{SD}$ \\
\hline \multicolumn{3}{|l|}{ Precision } \\
\hline Repeatability (recovery $\% \pm S D)^{a}$ & $\begin{array}{l}101.85 \pm \\
1.16\end{array}$ & $\begin{array}{l}97.70 \pm \\
0.65\end{array}$ \\
\hline $\begin{array}{l}\text { Intermediate precision (recovery } \% \pm \\
\text { SD) }\end{array}$ & $\begin{array}{l}101.10 \pm \\
0.94\end{array}$ & $\begin{array}{l}98.03 \pm \\
0.54\end{array}$ \\
\hline Accuracy (recovery $\% \pm S D)^{b}$ & $\begin{array}{l}100.28 \pm \\
0.92\end{array}$ & $\begin{array}{l}97.81 \pm \\
0.60\end{array}$ \\
\hline Lorinase syrup & $\begin{array}{l}101.50 \pm \\
1.10\end{array}$ & $\begin{array}{l}97.87 \pm \\
0.59\end{array}$ \\
\hline Clarinase tablets & $\begin{array}{l}102.40 \pm \\
0.86\end{array}$ & $\begin{array}{l}98.55 \pm \\
0.62\end{array}$ \\
\hline
\end{tabular}

${ }^{\mathrm{a}}$ Six replicates of samples at $100 \%$ level. ${ }^{\mathrm{b}}$ Triplicate injections each

\section{Discussion}

The use of cyanopropyl column offered an efficient alternative method that overcome the elution problems encountered when conventional reversed-phase chromatographic methods were used $[3,5]$; moreover, the developed method is simple and easy to use for routine analysis of the two analytes when presented in combined dosage forms upon comparison with method reported by Abu-Lathou et al. [4].

The results of one-factor-at-a-time (OFAT) studies suggested that optimum separation of the three compounds (LOR, PSE, and SB) is possible when the ionic strength is in the range of $10-20 \mathrm{mM}$ and $\mathrm{pH}$ range $3.0-5.0$, and acetonitrile is more than $70 \% \mathrm{v} / \mathrm{v}$. Based on these results, it has been decided to use multivariate response surface methodology approach for the separation process optimization. The Box-Behnken design was chosen because it is economical, rotatable, or semirotatable [10].

The statistical model parameters obtained from ANOVA of two responses after backward elimination are reported in Table 5. Since the prediction regression coefficient $\left(R^{2}\right)$ and adjusted regression coefficient $\left(R^{2}\right.$ adjusted) values for the two models were in close agreement, and the adequacy of precisions were $>4$, these model can be used to navigate the design space [15]. The design space generated through Derringer's desirability function was portrayed in Fig. 2, indicating high method performance owing to maximum desirability

Table 4 System suitability parameters from optimization mixture analysis

\begin{tabular}{llll}
\hline Analyte & $\begin{array}{l}\text { Resolution } \\
\left(\mathbf{R}_{\mathbf{s}}\right)\end{array}$ & $\begin{array}{l}\text { Asymmetry factor } \\
\left(\mathbf{A}_{\mathbf{s}}\right)\end{array}$ & $\begin{array}{l}\text { Theoretical plates } \\
(\mathbf{N})\end{array}$ \\
\hline SB & - & 1.01 & 4760.5 \\
LOR & $4.25 \pm 0.3^{\mathrm{a}}$ & 1.06 & 5283.1 \\
PSE & $5.40 \pm 0.4^{\mathrm{b}}$ & 1.21 & 3204.7 \\
\hline
\end{tabular}

${ }^{\mathrm{a}}$ Resolution between SB and LOR. ${ }^{\mathrm{b}}$ Resolution between LOR and PSE
Table 5 Reduced response models and statistical parameters

\begin{tabular}{lllllll}
\hline & Parameter & & & & & \\
\cline { 2 - 7 } & $\mathbf{R}^{\mathbf{2}}$ adjusted & $\begin{array}{l}\mathbf{R}^{\mathbf{2}} \\
\text { prediction }\end{array}$ & $\mathbf{R}^{\mathbf{2}}$ & $\mathbf{P}$ & \%CV & $\begin{array}{l}\text { Adequate } \\
\text { precision }\end{array}$ \\
\hline$Y_{1}$ & 0.9062 & 0.6703 & 0.9464 & ${ }^{\circ} 0.0001$ & 7.64 & 17.316 \\
$\log \left(Y_{2}\right)$ & 0.6428 & 0.4975 & 0.6939 & ${ }^{\circ} 0.0001$ & 15.07 & 11.258 \\
\hline
\end{tabular}

value (equal to 1); accordingly, it was possible to conclude that there was a set of coordinates producing high desirability $(\mathrm{D}=1.0)$. These were $\mathrm{pH}$ of 4.5 , acetonitrile content of $77 \% \mathrm{v} / \mathrm{v}$ and ionic strength of $16.0 \mathrm{mM}$. The predicted response values corresponding to the latter value of $D$ were $Y_{1}=4.0$ and $Y_{2}=5.6$.

The predictability of the proposed model was further confirmed by the good agreement between the experimental and predicted responses, as shown in Table 6 .

The good separation between the analytes confirms the prediction efficiency of the model; the corresponding chromatograms of the optimization mixture, standard, syrup, and tablets are shown in Figs. 3a-d, respectively.

The values of LOQ of the analytes were below the lowest expected analyte concentrations in the samples; hence, determination of the two analytes with high precision and accuracy is possible at concentrations above their reported LOQ values.

The good agreements between the practically obtained system suitability parameters and the theoretically required ones confirm the method suitability [16].

\section{Conclusions}

The use of experimental designs approach enabled rational and reliable method optimization. The use of cyanopropyl column and the very simple, relatively cheap, and easy-to-prepare mobile phase enabled separation of the active principles and preservative within less than 6 min, despite their widely different properties. It was also possible to achieve their quantification in spite of the great concentration difference between the analytes (PSE: LOR up to $24: 1, \mathrm{w} / \mathrm{w}$ ). In addition it was proved that the method is sensitive, precise, and accurate, with regards to the mixture under investigation. The method can be confidently applied to the quality control of the two active ingredients even when sodium benzoate is present as a preservative in syrup formulations.

Table 6 Comparison of observed and predicted values of different objective functions under optimal conditions

\begin{tabular}{lllll}
\hline $\mathbf{p H}$ & Percent acetonitrile & lonic strength & \multicolumn{2}{c}{ Responses } \\
\cline { 3 - 5 } $\mathbf{4 . 5 0}$ & $\mathbf{7 7 . 0 0}$ & $\mathbf{1 6 . 0 0}$ & $\mathbf{Y}_{\mathbf{1}}$ & $\mathbf{Y}_{\mathbf{2}}$ \\
\hline Experimental value & & 4.15 & 5.45 \\
Predicted value & & 4.00 & 5.60 \\
Average error \% & & +3.75 & -2.67 \\
\hline
\end{tabular}




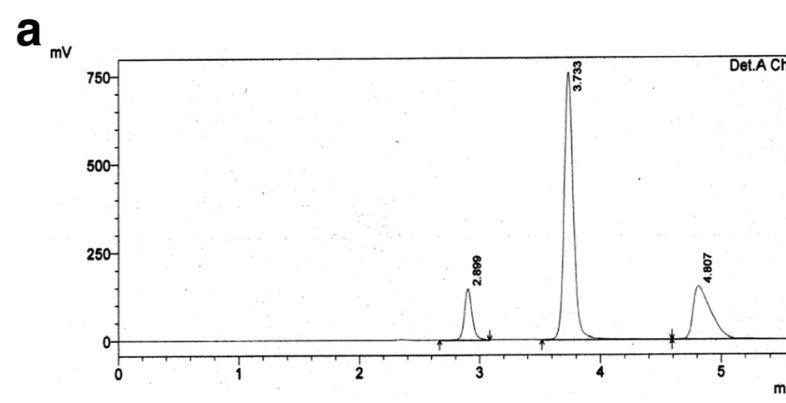

C

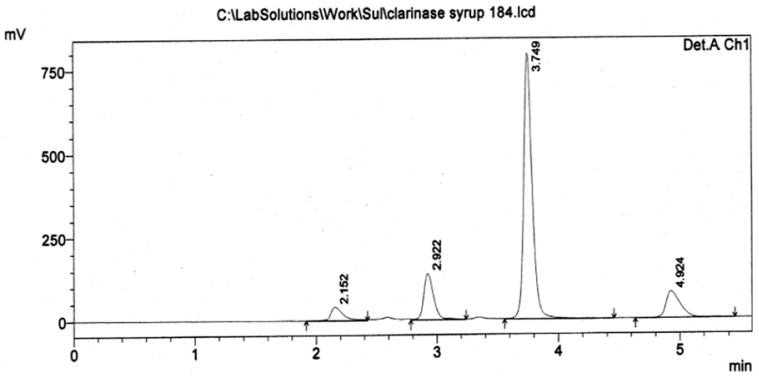

$\mathbf{b}_{\mathrm{m} /}$

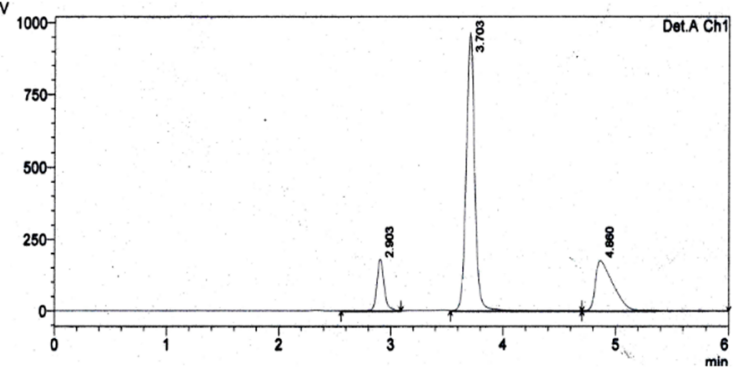

d

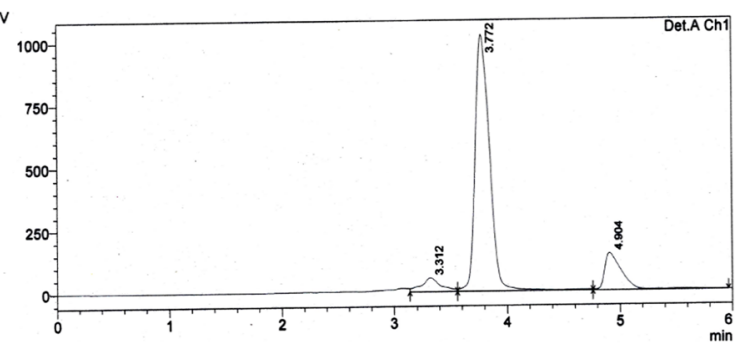

Fig. 3 Typical chromatograms of a optimization mixture, $\mathbf{b}$ standard solution, $\mathbf{c}$ Lorinase syrup, and $\mathbf{d}$ Clarinase tablets. SB $=2.90 \mathrm{~min}, \mathrm{LOR}=3.70$ $\min$, and PSE $=4.80 \mathrm{~min}$

\section{Abbreviations}

LOR: Loratadine; PSE: Pseudoephedrine; ACN: Acetonitrile; MP: Methylparaben; PP: Prorylparaben; SB: Sodium benzoate; ICH: International Conference on Harmonization; LOD: Limit of detection; LOQ: Limit of quantification; $R_{s}$ : Resolution; $A_{s}$ : Asymmetry factor; N: Number of theoretical plates; sd: Standard deviation; \%RSD: Percent relative standard deviation; $R^{2}$ adjusted: Adjusted regression coefficient; $R^{2}$ : Regression coefficient; $R^{2}$ prediction: Prediction regression coefficient; $D$ : Derringer's desirability function

\section{Acknowledgements}

Authors acknowledge the support provided by the staff of Department of Pharmaceutical Chemistry, Faculty of Pharmacy, Khartoum, Sudan, for the present work.

\section{Author's contributions}

The author read and approved the final manuscript.

\section{Funding}

No funding was received for this research work.

\section{Availability of data and materials}

All data and materials are available upon request.

\section{Declarations}

Ethics approval and consent to participate

Not applicable

\section{Consent for publication}

Not applicable as our study does not include patients

\section{Competing interests}

The author declares that there is no conflict of interests regarding the publication of this paper.
Received: 28 April 2021 Accepted: 18 June 2021

Published online: 08 July 2021

\section{References}

1. Sweetman SC (2009) Martindale: The Complete Drug Reference, 36th edition. Pharmaceutical Press, London

2. Moffat AC, Osselton MD, Widdop B (2011) Clarke's Analysis of Drugs and Poisons, 4th Edition. Pharmaceutical Press, London

3. Singhavi I, Bhatia N (2006) Spectrophotometric and HPLC method for simultaneous estimation of pseudoephedrine hydrochloride and loratadine from tablets. Indian J Pharm Sci 68(1):27-75. https://doi.org/10.4103/0250-4 $74 \times .22968$

4. Abu-Lathou A, Hamdan II, Tahraoui A (2005) A new HPLC approach for the determination of hydrophilic and hydrophobic components: the case of pseudoephedrine sulphate and loratadine in tablets. Drug Dev Ind Pharm 31:577-588. https://doi.org/10.1080/03639040500214696

5. Mabrouk MM, El-Fatatry HM, Hammad S, Wahbi AM (2003) Simultaneous determination of loratadine and pseudoephedrine sulphate in pharmaceutical formulation by RP-LC and derivative spectrophotometry. J Pharm Biomed Anal 33(1):597-604. https://doi.org/10.1016/s0039-914 0(99)00256-8

6. Palabiyik IM, Onur F (2007) Simultaneous spectrophotometric determination of pseudoepedrine sulphate and loratadine in a pharmaceutical preparation using chemometric techniques. J Fac Pharm Ankara 36(3):171-182

7. Culzoni MJ, Goicoechea HC (2007) Determination of loratadine and pseudoephedrine sulphate in pharmaceutical based on non-linear secondorder spectrophotometric data generated by a ph-gradient flow injection technique and artificial neutral networks. Anal Bioanal Chem 389:2217-2225. https://doi.org/10.1007/s00216-007-1656-6

8. Sane RT, Francis M, Khedkar S, Pawar S, Moghe A (2001) Simultaneous HPTL $\mathrm{C}$ determination of pseudoephedrine sulfate and loratadine from their combined dosage form. Indian Drugs 38(8):436-438

9. Abu Reid IO, Gadkariem EA (2017) Simultaneous determination of pseudoephedrine and loratadine in syrups by HPLC using cation exchange column and experimental design optimization. J Pharma Inov 6(3):244-247

10. Box GEP, Behnken DW (1960) Some new three-level designs for the study of quantitative variables Technometrics 2:455-475. https://doi.org/10.2307/12 66454 
11. ICH (2005) ICH topic Q2 (R1) validation of analytical procedure: text and methodology

12. Snyder LR, Kirklan JJ, Glajch JL (1997) Practical HPLC Method Development, 2nd edition. John Wiley and Sons Inc., USA

13. De Smet M, Massart DL (1987) Retention behaviour of acidic, neutral and basic drugs on a CN column using phosphate buffers in the mobile phase. J Chromatography 410:77-94. https://doi.org/10.1016/S0021-9673(00)90035-9

14. Derringer G, Suich R (1980) Simultaneous optimization of several response variables. J Qual Technol 12:214-219. https://doi.org/10.1080/00224065.1 980.11980968

15. Montgomery DC (1997) Design and analysis of experiments, 4th edn. John Wiley, New York, NY

16. Jenke JR (1996) Chromatographic method validation: a review of current practices and procedures. Part III. Ruggedness, revalidation and system suitability. J Liq Chromatogr Relat Technol 19(12)1873-1891. https://doi. org/10.1080/10826079608014012

\section{Publisher's Note}

Springer Nature remains neutral with regard to jurisdictional claims in published maps and institutional affiliations.

\section{Submit your manuscript to a SpringerOpen ${ }^{\circ}$ journal and benefit from:}

- Convenient online submission

- Rigorous peer review

- Open access: articles freely available online

- High visibility within the field

- Retaining the copyright to your article

Submit your next manuscript at $\boldsymbol{\nabla}$ springeropen.com 